\title{
Men, Women and Beasts: Relations to Animals in Western Culture
}

\author{
Rosemary Radford Ruether \\ Garrett Evangelical Theological \\ Seminary \\ Evanston, Illinois
}

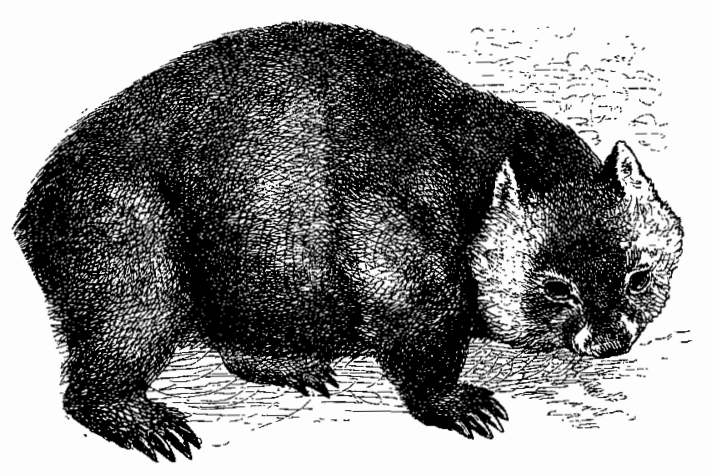

\section{Man the Hunter? \\ The Paleoanthropological Evidence}

Much of Western anthropology, since its origins in the 19th century, has emphasized "man the hunter" and has seen in males hunting animals the primary roots of human culture. This view has put a deep mark on exhibits in museums of anthropology and thereby on the public image of human "nature" and development. There is reason to question this view.

First, humans belong to the ape family. Early hominids split from their common ancestors with apes about 4 million years ago. Baboons and chimpanzees are primarily herbivores and insect eaters, who eat other animals occasionally, roughly about $5 \%$ of their diet. The human digestive tract remains that of its herbivore ancestors, and humans lack the canine teeth of baboons to strip meat from bones. While early hominids, like other apes, occasionally ate animals, for perhaps three million years these were generally not large, but small or weak, young animals, or the scavenged bodies of animals already dead.

It is interesting that this scavenging aspect of early hominid meat-eating and the killing of rodents or baby

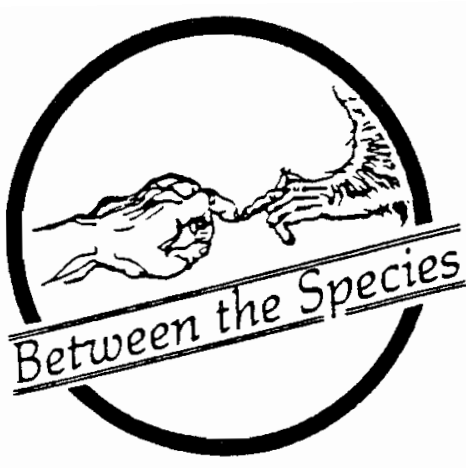

animals have been entirely ignored in popular culture. Clearly it doesn't lend itself to the same ideology of male dominance and aggression as does that of "man the hunter" going up against mammoths with spears. Only when stone tools developed could humans strip meat effectively from bones. Later, fire aided humans in the digestion of meat by allowing them to roast it.

Large-scale hunting awaited the development of more sophisticated hunting weapons, roughly about half a million years ago. But for most of the last two million years of human development, humans lived in small, fairly stable, hunting-gathering communities. Although the ratio of animal food to plant food varied with the environment, the general pattern in the tropics, where humans first developed and predominated until about 100,000 years ago, was one in which female plant-gathering activity accounted for about $70 \%$ of the human diet.

Women were seen as owning and controlling the houses of the village, as well as the food supply they gathered and processed. Meat from male hunting was given high status, but in fact the males often returned empty-handed. A strong ethic of sharing controlled relations of all members of the village. Food was not saved or stored or regarded as the private possession of individual households. A rough equality of labor and power seems to have prevailed between men and women in most of these societies.

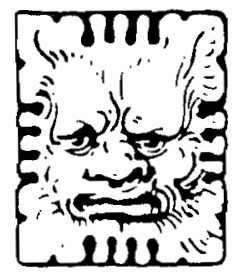

HISTORY OF IDEAS 
Ice age art in the caves of Europe gives us a tantalizing glimpse of the relation of hunter-gatherers to the animal world during this period of $35,000-15,000$ years ago. It was once thought that the vivid and dramatic pictures of bison and horses that adorn the walls of these caves were expressions of hunting magic, designed to put the animals in the control of humans to be killed. But then it was noticed that the animals depicted in the murals were not the ones predominantly hunted and eaten.

This suggests that the murals express much more of a mystic identification between humans and these animals, rather than a strategy for killing them. Very few human figures are depicted, and those are largely stick figures. Perhaps this means that humans were not focusing on themselves as an exalted separate species, but rather absorbing themselves in communion with an animal world that seemed to them much more wonderful than themselves.

The period after the Ice Age, from about 15,000 years ago, saw the transition from hunting-gathering to pastoral and agricultural ways of life. Hunters following herds of animals would cull out a few to kill and eat. Gradually they began to manage the whole herd, and to see themselves as owners of the animals. Likewise, gathering bands harvesting wild grains began to replant some of the seeds they gathered. This transition to domestication of animals and plants changed the human relationship to animals, to land and to each other.

The hunter-gatherer gender division of labor seems to have carried over into males being the owners of the herds of animals. Where this was the predominant food supply, a patrilocal and patrilineal pattern often developed, with the male head of household trading herd animals for wives and seeing both women and animals as patrimonial wealth. Domestication of plants was probably developed by women. Where this predominated, women continued to be seen as owning the household and controlling the food supply in early agricultural villages. But this seems to have changed as villages were linked together by more organized urban centers in the first city cultures.

About 8,000-3,000 B.C. male priestly and warrior elites developed and subjugated the population of surrounding villages. Tributary relations and slavery developed over conquered populations. Public works, such as irrigation systems, allowed these elites to control the water supply and to demand a part of the grain harvest, which became stored wealth in temple compounds. It is very likely that, in these early urban agricultural civilizations, meat eating began to reflect the new social and gender hierarchy. Although ordinary people might have a few domestic animals, the aristocracy set aside parks with herds of deer and other large animals, which they alone were allowed to hunt and eat.

Thus, I suggest, early urban states linked together four phenomena in close relation; organized warfare, and domination of women, of conquered people and of animals. Ownership and control became the model of relationship to all of these "other" groups, which also accounts for the tendency to equate the three groups symbolically, i.e., to equate women and slaves with "beasts" and to equate conquered men with women. Perhaps yoking animals to the plow and driving them with whips also suggested that such plow animals were a type of slave, and slaves, who were similarly chained and driven to pull large stones for public works, were "beasts."

\section{Hebrew and Greek Views of Animals}

The Hebrews were patriarchal pastoralists who settled in and claimed the land of the early agricultural and urban civilization in Palestine in the last centuries of the second millennium B.C. They developed a concept of a patriarchal god who had covenanted with them and made them his elect people. He also imposed strict moral obligations on his people, having to do both with avoidance of the cults of the neighboring Canaanite people, whose lands the Hebrews sought to conquer and settle, and with cultic and moral obligations that related the various categories of people among the Hebrews to each other.

These obligations included relations to animals. Hebrew law established a strict line between clean and unclean animals. Only the former were to be eaten. The exact basis for ruling out certain animals and marine life as unclean is uncertain, but some of the strictures against eating certain animals, such as pigs or calves boiled in milk, probably had to do with their sacred status in the cults of neighboring peoples. Those animals that were to be eaten were to be butchered in such a way as to drain the blood. The warm blood of mammals was seen as the same as that of humans, and so this law had to do with avoiding drinking blood as the life force which humans and animals shared.

The Hebrew god was seen as the creator of the earth, who has made all parts of it "very good" and who 
exercizes dominion over it. Humans were seen as separated from the rest of the animal world by being made in the "image" of this god. This meant that humans (actually, male heads of family) shared in this dominion of God over the animal and plant world. This concept of dominion probably did not mean that (male) humans were thought of as having wide powers over the whole of nature. Moreover, that dominion which they were to exercize over the world of domesticated animals and plants was as servants and delegates of God, and not as owners in their own right. This surely was understood in terms of (male) humans as good caretakers of the animals and plants of the earth, and not as exploiters or destroyers of them.

In the first chapter of Genesis humans are given all seed-bearing plants and fruits for food. The animals, birds and reptiles are given the green plants for food. No animals are given as food for humans or for each other. This suggests that, in the original state of innocence, humans and even animals were vegetarians! Only after the corruption of humans in cities, and the flood by which God punished the wicked generation of early urban people, were clean animals and birds offered as sacrifices to God and given as food for humans.

This advent of animal sacrifice and meat-eating is depicted as a distinct worsening both of human morals and of relations to animals. The inclination of the human heart is said to be "evil from its youth," and "the fear and dread of you shall rest on every animal of the earth and on every bird of the air, on everything that creeps on the ground, and on all the fish of the sea; into your hands they are delivered. Every moving thing that lives shall be food for you, and just as I gave you the green plants, I give you everything" (Gen 8:21; 9:2-3).

Meat-eating within limits is now justified, but as a distinct fall from original grace. Moreover, lumans (Hebrews) still are to be good caretakers and not exploiters of domesticated animals. These animals are seen as sharing in the covenant between God and Israel and hence in the right to rest on the Sabbath. Sons and daughters, male and female slaves and livestock are all included in the mandate for Sabbath rest (Exodus 20:10).

Moreover, every seven years, as a kind of atonement for the agricultural, animal-and-slave-holding way of life, Hebrews were mandated to return for one year to the gathering life, letting the fields lie fallow, not working the animals, and allowing humans and domesticated and wild animals to feed on what comes up from the fields on its own. This is also a time for the cancelation of debts, the release of (Hebrew) slaves who had fallen into servitude and for the return of land that had been alienated from poor farmers (Lev. 25).

Although the Hebrew (males) saw themselves as having been given a delegated dominion over the animals, they also saw themselves as kin of animals and of the earth. The name for human, Adam, means earth creature, the one who comes from the clay soil. Warm blood and sexual differentiation are characteristics humans share with mammals, and not with God. Like animals, humans are finite. A long healthy life, a just society in which enmity between humans and between humans and animals is overcome, where all God's creatures live in harmony with each other, this is the Hebrew vision of salvation.

By contrast, Greek culture moved to a more rigid notion of the superiority of the human to the animal, by virtue of his "rational" soul, and sought to establish an origin and destiny for this soul above the embodied world. This rigid separation of human and animal was not true in pre-classical Greek culture, which preserved remnants of an earlier worldview where the gods flowed between human and animal forms. Memories of a more matricentric world lingered in stories of powerful queens, amazons and goddesses. Half-animal, halfhuman figures, such as satyrs and centaurs, preserved a wilder, animal-identified life.

But, in classical Greek culture this view of the female and the animal, as powerful, mysterious others, slifts to a hierarchical worldview in which women, slaves and animals are lined up in descending order of inferiority under the ruling Greek male. The rational soul is seen as both the principle of rule over these inferiors and of ultimate escape from the mortality of the body.

This is made explicit in Plato's creation story, the Timaeus, where the human souls are seen as partaking in the same substance as the world soul, which the Creator infuses into the body of the cosmos as its principle of ordered motion. The remains of this soul substance are divided into pieces and placed in the stars to contemplate the eternal ideas. Only afterwards are these souls infused into bodies, created for them by the planetary gods, and placed on earth.

This embodied state is seen as a temporary testing period in which the soul is to learn to control the passions that arise from the body. If it succeeds in doing this, it will be freed from the body at death and return to a happy existence in its native star. But if it succumbs to the passions of the body, it will be reincarnated into 
a woman or into some animal that resembles the "low state to which it has fallen." It must then work its way up through reincarnations until it becomes again a (ruling class Greek) male and can be freed from the cycle of reincarnation.

This hierarchy of ruling Greek male over female, slave and animal, as a relation of mind over body, is also made clear in Aristotle's treatises on politics and on the generation of animals. Here females are the prototype of that subhuman who lacks by nature the capacity for reason and self-rule and hence is a natural slave. Conquered people are then associated with this same slave condition that is the "natural" condition of the female. Animals and tools are identified as extensions of the relationship of the ruling male to those people and things which are instrumentalized as means of labor under his control and for his benefit.

\section{Classical Christian Views of Animals}

Classical Christianity inherited both the Hebrew view of (male) human dominion over the animals and the Greek view of the transcendence of the (inale) rational mind or soul over the body, the woman and the animal. Over the first several centuries of its development Christianity marginalized the Hebrew vision of salvation as a future time on earth of justice between humans and harmony with animals. Instead, it focused its hopes on the escape of the soul from its encasement in the mortal body and its ascent to a transcendent world above.

Scholastic theologians, such as Thomas Aquinas, reflected the Aristotelian tradition when they declared that animals have no moral standing of their own because they lack rational souls. Humans have unlimited rights to use animals for food or labor. The only reason for not abusing animals is because humans corrupt themselves and learn to be cruel to each other by being cruel to animals.

However, another minority view of animals is found in certain lines of the monastic tradition. Here the monk is seen as a kind of holy "wild man" who rejects civilization and its luxuries and returns to a gathering or subsistence economy in the wilderness. In reclaiming the paradisal lifestyle, the monk overcomes enmity with the animal world. Birds bring him bread, as he remains transfixed in prayer, and wolves befriend him. The tradition of Francis of Assisi, with his friendship with birds and wolves, lies in this monastic tradition of return to nature. Traditionally monks ate no meat, a practice which also had roots in the Pythagorean vegetarian tradition, which saw meat-eating as exciting the"passions."

\section{Changing Views of Animals in England 1600-1850}

Renaissance and Reformation England and Western Europe inherited these scholastic views of animals as lacking moral standing because of their lack of "souls." This instrumentalization of animals was carried to an extreme in the philosophy of Descartes who insisted that animals feel no pain. Even though they may howl when butchered or dissected in laboratories, these are just reflexes. The animal is basically a complex machine which lacks any interior animate principle and so can be regarded as a mere automaton that can be exploited, not only for food and labor, but now as subjects of scientific experiments.

This concept of the animal as lacking moral standing was correlated with a more rigid subordination of women in the patriarchal nation state, as women lost some of the work and property rights they had enjoyed in feudal, land-holding and guild societies. There was a new emphasis on the subordination of women to men in the family and on their exclusion from public political rights. This was also the period of the revival of slavery, with the expansion of Europe into colonization of Africa and the Americas. The status of Africans and Amerindians as fully human was widely denied. It was claimed that they were "semi-brutes" lacking equal humanity with Europeans.

Stuart England saw a new interest in natural science and with it the effort to classify animals and plants scientifically. Medieval bestiaries, with their animal symbolism based on moral categories, were rejected in favor of Latin names and objective divisions into genera and species. This interest in classificatory knowledge was seen as an extension of (male) human control over nature. In Baconian thought nature known and subinitted to control by the male rational mind was nature "redeemed."

At the same time traditions of "blood sports" continued among the upper and lower classes. Among lower classes bull-baiting and cock-fighting were popular entertainment. The aristocracy kept to itself large parks where their members alone were allowed to hunt and kill animals. Hunting, particularly riding 
to hounds, was closely linked with the military ethos of the nobleman, as it continues to be in England today.

At the same time there was a new rage among the aristocracy for pets, especially lap dogs. Dogs and horses owned by the nobility were assimilated into the aristocratic ethos by constructing animal pedigrees. Breeding "thoroughbred" and "pure bred" animals, whose blood lines are traced through a line of noble "sires," established the animals owned by the nobility as aristocrats, strictly separated from the "curs" and "mongrels" owned by the lower class. Animal hierarchy was thus made to mirror human hierarchy. Animals were given official names. Favorites had their portraits painted, elegies written and tombs provided for them at their deaths.

The 18th and 19th centuries in England saw the rise of a distinct middle-class sensibility toward animals, pioneered by Puritans and Evangelicals, that separated itself from both aristocratic and popular blood sports. These evangelicals campaigned especially against the cock-fighting and bull-baiting of the lower classes, partly in aversion to the cruelty to the animals themselves, but also because such sports were seen as inciting the unruly "instincts" of the "lower orders" and thus as inimical to good order and social control.

Organizations, such as the Society for the Prevention of Cruelty to Animals, sought to outlaw such blood sports. Anti-vivisection societies arose to protest the dissection of live animals in laboratories. These middleclass reformers were remote from the rough and ready relation to animals of rural farm people, as well as the rural life of the aristocracy. Their relation to animals was primarily to pets. Some evangelicals upheld the view that intelligent mammals had moral feelings like humans and their souls could be expected to survive death. John Wesley, founder of Methodism, was among those who contended that animal sentience indicates that animals have immortal souls.

This campaign against cruelty to animals was closely associated with parallel campaigns against cruelty to prisoners and for the abolition of slavery. The humane treatment of the poor in poor houses, of the insane in mental hospitals and of the imprisoned, the quest to abolish cruel punishment of criminals by mutilation, flogging and torture, went hand-in-hand with the abolition of cruelty to animals. Recognition of the humanity of the slave or servant and the sentience of the animal were part of an ethic of humanitarianism, which was often combined with a certain paternalism toward those seen as under the care of the "good master."

\section{Toward an Ethic of Animal Rights}

As James Serpell pointed out in his book, In the Company of Animals, Western (English and American) views of animals are deeply dichotomous. On the one hand, we inherit the Scholastic-Cartesian view that animals lack moral standing and exist only for human use. The feelings of animals need not be considered, either in laboratory experiments or in factory-farming of animals for meat. Animals in these contexts are simply material objects to be used for human needs, for medical experiments that promote human health or for the meat pièce de résistance of the meal, presumed to be necessary for the healthy diet.

On the other hand, another category of animals, particularly cats and dogs but also other assorted mammals, reptiles, birds and fish, are adopted into the human household. It is the assumed responsibility of the pet owner to give the pet the best of care, regular, balanced diet and clean living conditions. The neglected pet can be seized by state authorities and the pet-owner fined for cruelty or neglect. Certain animals, particularly cats and dogs, are given more than this. They are seen as kin and permanent children of the family. The affection lavished on these animals is closely associated with the ability of these animals to be responsive to human affection and to bond with humans.

The notion that animals feel no pain or that it is not cruel to torture them in laboratories or subject them to a confined and terrorized existence in factory farms is directly contradicted by this quasi-kinship relation to the family pet. Modern societies mask this contradiction in several ways. Laboratory treatment of animals is shielded from the public gaze, and it is seen as part of the scientific ethic to be able to put aside such feelings for "science."

Likewise, most meat-eating people have no direct experience with the conditions of the factory farm or the slaughterhouse. Whole animals, with head and feet, no longer hang in butcher shops to confront us with the reality of the animal corpse. Instead, the meat comes to us sanitized, in plastic-wrapped packages, which allows the meat-eater to disassociate the meat from its reality as pieces of animal flesh. Only fish still retain their eyes and fins in the supermarket. But these are usually dismembered on the spot, so the shopper carries home 
only the portions stripped of head, skin and fins. In short, we carefully keep ourselves from looking into the eye of the animal we are to eat.

Animal rights activists basically seek to make this contradiction visible, audible and emotionally present. They portray the sufferings of the animal caged in the factory farm, the terrorized animal in the slaughterhouse, and the maimed, dazed animal in the laboratory, and make us identify our kinship feelings for the pet animal with these hidden victims of exploitation. They seek to evoke the same moral and emotional feelings of revulsion for this treatment of farm and laboratory animals as we would feel if such treatment were meted out to the beloved family dog or cat. Although they appeal to the libertarian tradition of legal "rights" for all humans, seeking to extend these rights to animals that share a common sentience with humans, their emotional, motivational power lies in this relation of humans to pets.

This evocation of human bonding with pets on behalf of suffering animals in laboratories, factory farms and slaughterhouses is, I believe, quite proper. Human relationship with family pets should not be trivialized; it should be taken seriously. It is the major opportunity that most people in industrialized societies have to experience a cross-species relationship between humans and animals. The pet dog or cat is, in many ways, a colonized animal, often overbred in an unhealthy fashion, reduced to forced leisure and assimilated into a totally human environment, mostly denied relationships with other animals of its own species. Yet it is the one place humans interact with beings of other species and experience personhood in nonhuman forms. However unnatural this relation is, it is a major experiential resource to arouse us to concern about animal suffering.

Still, the question can well be asked whether it is enough. Can the language of personal rights and the appeal to a common sentience carry us into a broad enough concern with what modern industrial society is doing to the nonhuman world? I would suggest that its appeal is valid, but limited. It can arouse us to concern for certain categories of animals, the kind of sentient mammals with which humans can feel bonding and kinship. It has little power when the issue becomes the preservation of vanishing species of fish, reptile or insect. This is not a criticism so much as an indication that our relationship with the nonhuman world is so fragmented and disconnected that we need to use different ethical and motivational appeals in different contexts.

\section{Bibliography}

Adams, Carol J., The Sexual Politics of Mear: A FeministVegetarian Critical Theory (NY: Continuum, 1990).

Cobb, John, Matters of Life and Death (Louisville, KY: Westminster/John Knox Press, 1990).

Collard, Andre, with Joyce Contrucci, Rape of the Wild: Man's Violence against Animals and the Earth (Bloomington, IN: Indiana University Press, 1989).

DuBois, Page, Centaurs and Amazons: Women and the PreHistory of the Great Chain of Being (Ann Arbor, MI: University of Michigan Press, 1982).

Ehrlich, Paul and Anne Ehrlich, Extinction: The Causes and Consequences of the Disappearance of Species (NY: Randon House, 1981).

Kheel, Marti, "Animal Liberation and Environmental Ethics: Can Eco-feminism Bridge the Gap," paper given at the Western Political Science Association, San Francisco, CA, March 10-12, 1988.

Leakey, Richard E., The Making of Mankind (NY: E.P. Dutton, 1981).

Linzey, Andrew, Christianity and the Rights of Animals (NY: Crossroads, 1987).

McDaniel, Jay, Of God and Pelicans: A Theology of Reverence for Life (Louisville, KY: Westminster/John Knox Press, 1989).

Martin, M. Kay and Barbara Voorhies, Female of the Species (NY: Columbia University Press, 1975).

Regan, Tom, The Case for Animal Rights (Berkeley, CA: University of California Press, 1983).

Serpell, James, In the Company of Animals: A Study of HumanAnimal Relationships (London: Basil Blackwell, 1986).

Shepard, Paul, Nature and Madness (San Francisco, CA: Sierra Club Books, 1982).

Singer, Peter, Animal Liberation (NY: Avon, 1975).

Tanner, Nancy Makepeace, On Becoming Human (London: Cambridge University Press, 1981).

Thomas, Keith, Man and the Natural World: Changing Attitudes in England, 1500-1800 (NY: Penguin, 1984).

Wilson, Edward O., Biophilia (Cambridge, MA: Harvard University Press, 1984). 